\title{
Editorial
}

\section{The road to indexing!}

\author{
Jean-Christophe Fricain
}

At the time of the current political shakeup, I could not help but take advantage of this editorial space to review the history and future of the journal Médecine Buccale, Chirurgie Buccale $(M B C B) . M B C B$ is the official mouthpiece and property of the French Society of Oral Surgery. It was launched more than 20 years ago, but only began regularly publishing four issues a year in 2005, thanks to the perseverance and talent of Jacky Samson. He was the editor for 10 years and contributed to the addition of MBCB to an indexing database for the first time, i.e., the Copernicus Index. In 2012, Jacky Samson requested me to assist him in his role as an editor-in-chief. Starting in 2013, the journal took measures to comply with the requirements of the International Committee of Medical Journal Editors (ICMJE). ICMJE defines the uniform requirements for manuscripts submitted to biomedical journals. These rules concern ethical considerations on research and publications, the rules relating to publishing and writing in biomedical journals, and the preparation and submission of manuscripts with references [1]. The year 2013 also saw the first online submission of the articles, thanks to the editorial manager system used by the majority of international journals. This system handles the submission and proofreading before transferring the articles to the production unit, and it also allows the editors to designate two anonymous reviewers. At the end of this process, the article may be accepted, rejected, or returned to the corresponding author for corrections and improvements. Before sending the articles to production, the editors perform the finishing work of the article, which consists of ensuring that the formatting of the articles is compliant with the journal style. In 2014, Philippe Lesclous replaced Jacky Samson. The next year, i.e., 2015, was a turning point in the history of $M B C B$ when all articles published since 2001 were available for open access. This move to open access has had the immediate effect of increasing the readership of $M B C B$, as evidenced by the increase between 2014 and 2016; the number of unique visits increased from 12,650 to 63,685 in France, from 5,467 to 26,530 in French-speaking Africa, from 1,030 to 5,218 in North America, and from 895 to 3,950 in Belgium and Switzerland. We have also seen a fivefold increase in downloads over these 2 years, with close to 45,000 in 2016 . These figures reflect the vibrance of the journal as a vital member in the national and international world of oral medicine and surgery. All these efforts in 2016 contributed to $M B C B$ being referenced in the transdisciplinary database SCOPUS, which indexes more than 22,000 journals. The selection of journals indexed in SCOPUS is based on strict criteria for the clear and transparent evaluation of peer-reviewed articles, regular publication with an ISSN number, a publication history of $>2$ years, content readable by an international audience, a fair ethics policy, and fair advertising.

Being indexed in SCOPUS and being available on open access are guarantees of increased readership of $M B C B$. However, it is still vital that the journal is indexed PubMed and Medline indexes. These databases are the most used in the medical world, and as Professor Louis Maman, Chief of Dentistry of the Charles Foix Hospital, mentioned once, [2] points in the System for the Identification, Management and Analysis of Scientific Publications (SIGAPS) are calculated from publications referenced in PubMed and are useful when financing hospital structures. This implies that a French language journal needs to become an English language journal. As a first step, for maintaining the French-speaking component, we propose that the publisher takes care of the translation of the accepted articles. To compensate for this cost, we decided to stop print publications from 2017. This translation by the publisher is of immense help to the authors, but we encourage all authors to submit your work directly in English. We cannot ignore the fact that scientific and medical publications exist

\footnotetext{
*Correspondance : fricainj@aol.com

This is an Open Access article distributed under the terms of the Creative Commons Attribution License (http://creativecommons.org/licenses/by/4.0), which permits unrestricted use, distribution, and reproduction in any medium, provided the original work is properly cited
} 
in a globalized world and that English has become the official language in this field as well. Hence, rather than remaining a French-only journal, I encourage that we all work together for PubMed indexing first, and then Medline indexing, by publishing in English in the new English title for the journal - Journal of Oral Medicine and Oral Surgery (JOMOS).

\section{References}

1. Uniform requirements for manuscripts submitted to biomedical journals: drafting and publishing of biomedical publication 2010. http://www.icmje.org/french.pdf

2. MbCb 2017. D0I: https://doi.org/10.1051/mbcb/2017007 